\section{Plant pathogens}

\section{Mitochondrial control of fungal hybrid virulence}

ybrid species of fungal pathogens that infect wild and cultivated plants are emerging with new virulence and host ranges, posing a threat to agriculture and forestry ${ }^{1}$. Here we show that the virulence of hybrid species of the basidiomycete fungus Heterobasidion annosum (Fr) Bref, a causal agent of root and butt rot in conifers and one of the most economically important forest pathogens, is controlled by their mitochondrial genome. Our results indicate that cooperation between organelles that contain genetic information may influence the phenotype of hybrid phytopathogens.

Among fungal plant pathogens, species hybrids have been discovered in Melampsora $^{2,3}$, Phytophthora ${ }^{4-6}$, Ophiostoma ${ }^{7}$ and Heterobasidion $^{8}$. In North America there are two intersterile groups of $H$. annosum that correspond to species with overlapping morphological characters and different ecological niches: the ' $\mathrm{S}$ ' group infects Abies spp. and Tsuga spp. ${ }^{9}$, whereas the 'P' group has Pinus spp. as its main hosts'. So far, only one natural S-P hybrid has been found ${ }^{8}-$ this isolate is less virulent than either of its progenitors to their 'adapted' host plant species but not to a universal host ${ }^{10}$.

We articially created four S-P hybrid heterokaryons (fungal mycelia that contain dissimilar nuclei), one S-S heterokaryon and one P-P heterokaryon from four North American homokaryotic $H$. annosum isolates (containing one nuclear type each; provided by T. E. Chase) and determined the severity of their effects on pine seedlings (Table 1).

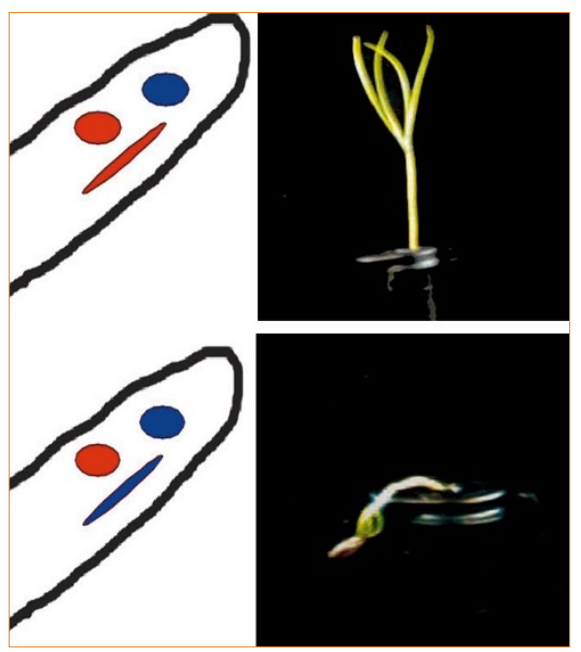

Figure 1 Virulence of S-P hybrids of the plant pathogen $H$. anno sum to pine seedlings. Virulence of hybrids is controlled by the mitochondrion (represented by ellipses) rather than the nucleus (circles). Blue denotes genomic inheritance from the P group, red from the $S$ group. Hybrids with mitochondria of $S$ origin do not kill the pine seedling (top), in contrast to hybrid mycelia with mitochondria of $\mathrm{P}$ origin (bottom).

\begin{tabular}{|c|c|c|c|c|}
\hline Isolate & Genotype & Nucleus type & Mitochondrial type & Mortality (\%) \\
\hline TC 32-1 & $A$ & $\mathrm{P}$ & $\mathrm{P}$ & 90 \\
\hline TC 39-7 & $B$ & $\mathrm{P}$ & $\mathrm{P}$ & 90 \\
\hline TC 122-11 & $\mathrm{C}$ & $S$ & $S$ & 31 \\
\hline TC 122-12 & $D$ & S & $\mathrm{S}$ & 34 \\
\hline $\mathrm{AO} 8$ & $A+D$ & $S+P$ & $S$ & 55 \\
\hline AO 9 & $B+D$ & $S+P$ & $\mathrm{P}$ & 86 \\
\hline AO 10 & $A+B$ & $P+P$ & $\mathrm{P}$ & 93 \\
\hline AO 11 & $C+D$ & $S+S$ & S & 28 \\
\hline $\mathrm{AO} 12$ & $B+C$ & $S+P$ & $S$ & 28 \\
\hline $\mathrm{AO} 13$ & $A+C$ & $S+P$ & $\mathrm{P}$ & 83 \\
\hline
\end{tabular}

Genotypes of the homokaryons and their combinations in heterokaryons are represented by the letters $A-D$. Nuclear types were confirmed by mating tests and by microscopic examination for clamp connections, which indicate heterokaryons. Mitochondrial types were determined from the intron size in the gene that encodes large-subunit ribosomal RNA (see text). Virulence is expressed as mortality rate among 29 pine seedlings for each isolate 20 days after inoculation with $1.7 \mathrm{ml}$ of mycelium suspension ( $0.5 \mathrm{mg}$ dried mycelia per $\mathrm{ml}$ of medium).

We analysed the virulence of the homokaryons and heterokaryons in vitro by visually scoring dead or live pine seedlings daily for 20 days $^{11}$. We observed no significant difference in virulence between homokaryons and heterokaryons of either the $\mathrm{S}$ or $\mathrm{P}$ intersterility groups $\left(P<0.05, \chi^{2}\right.$ test). This is consistent with earlier results suggesting that heterokaryosis of $\mathrm{H}$. annosum is not required for virulence ${ }^{12}$.

We scored S-P hybrids as having either low or high virulence to pine, which is characteristic of the $\mathrm{S}$ and $\mathrm{P}$ groups, respectively (Table 1). Isolates AO 9 and AO 13 did not differ significantly in virulence from $\mathrm{P}$ isolates, but were significantly different from isolates $\mathrm{AO} 8$ and $\mathrm{AO} 12$, and from $\mathrm{S}$ isolates $\left(P<0.05, \chi^{2}\right)$. Neither AO 8 nor AO 12 differed significantly from $S$ isolates, but they were different from $\mathrm{P}$ isolates $\left(P<0.05, \chi^{2}\right)$. If the virulence of a H. annosum hybrid were solely controlled by nuclear virulence genes or by avirulence genes, then all S-P hybrids should show either the high or low virulence that characterizes the respective intersterility groups.

Homokaryotic $H$. annosum S and P isolates differed in the size of an intron in the gene that encodes the large-subunit RNA of mitochondrial ribosomes, as revealed by amplification with the ML5-ML6 primer pair $^{8}$ (Table 1). The mitochondria of the hybrid isolates AO 8 and AO 12 were from the $\mathrm{S}$ homokaryon, whereas those of AO 9 and AO 13 were of $\mathrm{P}$ origin (Table 1). None of the S-P hybrids possessed both types of mitochondrion, showing that mitochondrial transmission was uniparental.

There was a perfect correlation between the mitochondrial type acquired by the hybrids and their virulence (Table 1; Fig. 1). Hybrids with mitochondria of $\mathrm{P}$ origin had similar virulence to $P$ homokaryotic progenitors, whereas the virulence of hybrids with $S$ mitochondria resembled that of $S$ homokaryons. To our knowledge, this is the first example of mitochondrial control of virulence in species-hybrid plant pathogens, although mitochondria are thought to be important in host specialization for Phy- tophthora nicotianae $\times$ P. cactorum hybrids ${ }^{5}$.

What is the source of this correlation between mitochondrial origin and the virulence of pathogenic fungal hybrids? It may be that the mitochondrial genome itself encodes factors that determine the virulence of hybrids, or that interplay between the organism's mitochondrial and nuclear genomes gives rise to a mitochondrially determined phenotype in hybrids.

\section{Åke Olson, Jan Stenlid}

Department of Forest Mycology and Pathology,

Swedish University of Agricultural Sciences,

SE-750 07 Uppsala, Sweden

e-mail:ake.olson@mykopat.slu.se

1. Brasier, C. Nature 405, 134-135 (2000).

2. Spiers, A. G. \& Hopcroft, D. H. Mycol. Res. 98, 889-903 (1994).

3. Newcombe, G., Stirling, B., McDonald, S. \& Bradshaw, H. D. Jr Mycol. Res. 104, 261-274 (2000)

4. Éresk, T., English, J. T. \& Schoelz, J. E. Phytopathology 85, 1343-1347 (1995).

Man in't Veld, W. A. et al. Phytopathology 88, 922-929 (1998).

6. Brasier, C. M., Cooke, D. E. L. \& Duncan, J. M. Proc. Natl Acad. Sci. USA 96, 5878-5883 (1999).

Brasier, C. M., Kirk, S. A., Pipe, N. D. \& Buck, K. W. Mycol. Res. 102, 45-57 (1998)

8. Garbelotto, M., Ratcliff, A., Bruns, T. D., Cobb, F. W. \& Otrosina, W. J. Phytopathology 86, 543-551 (1996).

9. Korhonen, K. \& Stenlid, J. in Heterobasidion annosum: Biology, Ecology, Impact and Control (eds Woodward, S., Stenlid, J., Karjalainen, R. \& Hüttermann, A.) 43-70 (CAB International, Wallingford, 1998).

10. Garbelotto, M., Popenuck, T., Ratcliff, A., Cobb, F. W. \&

Bruns, T. D. Phytopathology 86 (suppl.), 28-29 (1996).

11. Sharma, P., Börja, D., Stougaard, P. \& Lönneborg, A. Physiol. Mol. Plant Pathol. 43, 57-67 (1993).

12. Garbelotto, M. et al. Mycologia 89, 92-102 (1997).

\section{addendum}

A fern that hyperaccumulates arsenic

L. Q. Ma, K. M. Komar, Cong Tu, Weihua Zhang,

Yong Cai, E. D. Kennelley

Nature 409, 579 (2001)

It has been pointed out that other plants have been reported previously to take up and tolerate arsenic from soils $^{1-5}$, but we would like to stress that, unlike brake fern (Pteris vittata), none of these plants has been shown to hyperaccumulate arsenic - that is, the concentration of arsenic in their aboveground biomass was less than that in the soil and in the plant roots.

\footnotetext{
1. Porter, E. K. \& Peterson, P. J. Sci. Tot. Env. 4, 365-371 (1975).

2. De Koe, T. Sci. Tot. Env. 145, 103-109 (1994).

3. Bech, J. et al. Sci. Tot. Env. 203, 83-91 (1997).

4. Warren, H. V., Delavault, R. E. \& Barakso, J. Can. Min. Metal. Bull. 61, 860-867 (1968).

5. Meharg, A. A., Naylor, J. \& Macnair, M. R. J. Env. Qual. 23, 234-238 (1994)
} 


\title{
A fern that hyperaccumulates arsenic
}

\author{
A hardy, versatile, fast-growing plant helps to remove arsenic from contaminated soils.
}

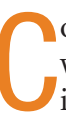
ontamination of soils with arsenic, which is both toxic and carcinogenic, is widespread ${ }^{1}$. We have discovered extremely efficient in extracting arsenic from soils and translocating it into its above-ground biomass. This plant which, to our knowledge, is the first known arsenic hyperaccumulator as well as the first fern found to function as a hyperaccumulator $^{2}$ - has many attributes that recommend it for use in the remediation of

We found brake fern growing on a site in Central Florida contaminated with chromated copper arsenate (Fig. 1a). We analysed the fronds of plants growing at the atomic absorption spectroscopy. Of 14 plant species studied, only brake fern contained large amounts of arsenic (As; $3,280-4,980$ p.p.m.). We collected additional samples of the plant and soil from the contaminated site (18.8-1,603 p.p.m. As) and from an uncontaminated site (0.47-7.56 p.p.m. As). Brake fern extracted arsenic efficiently from these soils into its fronds: plants growing in the contaminated site contained 1,442-7,526 p.p.m. arsenic and those from the uncontaminated site contained 11.8-64.0 p.p.m. These values are much higher than those typical for plants growing in normal soil, which contain less than 3.6 p.p.m. of arsenic ${ }^{3}$.

As well as being tolerant of soils containing as much as 1,500 p.p.m. arsenic, brake fern can take up large amounts of arsenic into its fronds in a short time (Table 1). Arsenic concentration in fern fronds growing in soil spiked with 1,500 p.p.m. arsenic increased from 29.4 to 15,861 p.p.m. in two weeks. Furthermore, in the same period, ferns growing in soil containing just 6 p.p.m. arsenic accumulated 755 p.p.m. of arsenic in their fronds, a 126-fold enrichment. Arsenic concentrations in brake fern roots were less than 303 p.p.m., whereas those in the fronds reached 7,234 p.p.m. that the fern Pteris vittata (brake fern) is arsenic-contaminated soils. site for total arsenic by graphite furnace

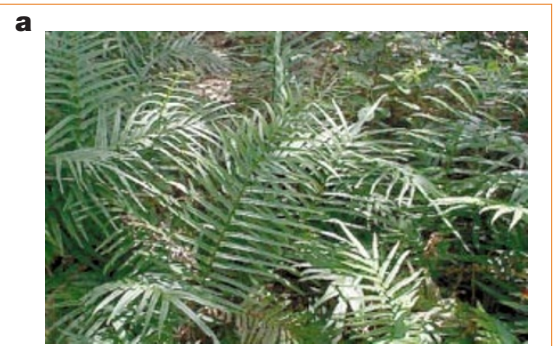

b

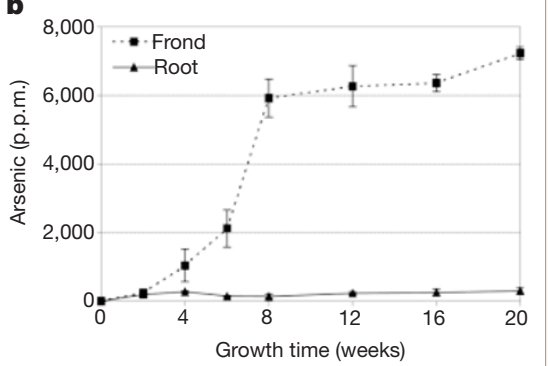

c

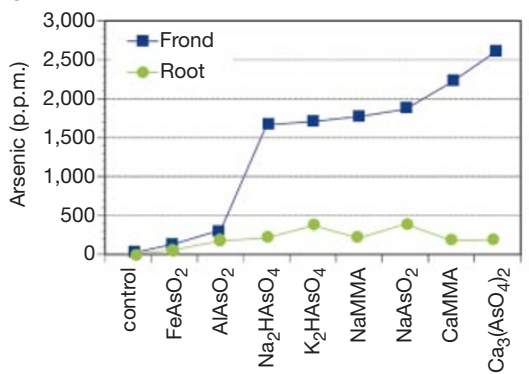

Arsenic species

Figure 1 Arsenic concentrations in brake fern growing in arseniccontaminated soils. a, Brake fern growing on an abandoned woodpreservation site contaminated with chromated copper arsenate (CCA); b, arsenic concentrations in brake fern after 20 weeks' growth in a CCA soil containing 97 p.p.m. As; and c, arsenic concentrations in brake fern after 18 weeks' growth in soil spiked with 50 p.p.m. As of various species. Brake fern plants grown in the laboratory were transferred to 2.5-litre pots (one plant per pot, with four replicates) containing $1.5 \mathrm{~kg}$ soil to determine arsenic-uptake changes with time and the arsenic species. NaMMA, monosodium methylarsonate; CaMMA, calcium acid methanearsonate.

(Fig. 1b). Addition of 100 p.p.m. arsenic significantly stimulated fern growth, resulting in a $40 \%$ increase in biomass compared

\section{Table 1 Arsenic concentrations in brake fern}

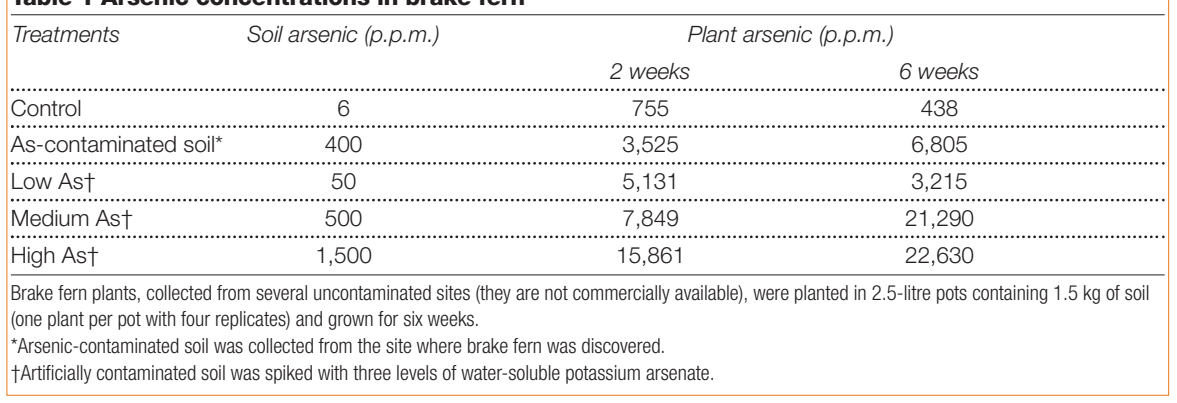

with the control (data not shown).

After 20 weeks of growth, the plant was extracted using a solution of $1: 1$ methanol:water to speciate arsenic with high-performance liquid chromatographyinductively coupled plasma mass spectrometry. Almost all arsenic was present as relatively toxic inorganic forms, with little detectable organoarsenic species ${ }^{4}$. The concentration of As(III) was greater in the fronds $(47-80 \%)$ than in the roots $(8.3 \%)$, indicating that $\mathrm{As}(\mathrm{V})$ was converted to As(III) during translocation from roots to fronds.

As well as removing arsenic from soils containing different concentrations of arsenic (Table 1), brake fern also removed arsenic from soils containing different arsenic species (Fig. 1c). Again, up to $93 \%$ of the arsenic was concentrated in the fronds. Although both $\mathrm{FeAsO}_{4}$ and $\mathrm{AlAsO}_{4}$ are relatively insoluble in soils ${ }^{1}$, brake fern hyperaccumulated arsenic derived from these compounds into its fronds (136-315 p.p.m.) at levels 3-6 times greater than soil arsenic.

Brake fern is mesophytic and is widely cultivated and naturalized in many areas with a mild climate. In the United States, it grows in the southeast and in southern California ${ }^{5}$. The fern is versatile and hardy, and prefers sunny (unusual for a fern) and alkaline environments (where arsenic is more available). It has considerable biomass, and is fast growing, easy to propagate, and perennial.

We believe this is the first report of significant arsenic hyperaccumulation by an unmanipulated plant. Brake fern has great potential to remediate arsenic-contaminated soils cheaply and could also aid studies of arsenic uptake, translocation, speciation, distribution and detoxification in plants.

Lena Q. Ma*, Kenneth M. Komar $†$,

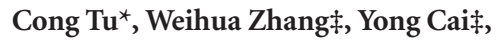
Elizabeth D. Kennelley*

* Soil and Water Science Department, University of Florida, Gainesville, Florida 32611-0290, USA

e-mail:lqma@ufl.edu

$\dagger$ Cooperative Extension Service, University of Georgia, Terrell County, PO Box 271, Dawson, Georgia 31742, USA

$\$$ Department of Chemistry \& Southeast Environmental Research Center, Florida International University, Miami, Florida 33199, USA

1. Nriagu, J. O. (ed.) Arsenic in the Environment Part 1: Cycling and Characterization (Wiley, New York, 1994).

2. Brooks, R. R. (ed.) Plants that Hyperaccumulate Heavy Metals (Cambridge Univ. Press, 1998).

3. Kabata-Pendias, A. \& Pendias, H. in Trace Elements in Soils and Plants 203-209 (CRC, Boca Raton, 1991).

4. Koch, I., Wang, L., Ollson, C. A., Cullen, W. R. \& Reimer, K. J. Envir. Sci. Technol. 34, 22-26 (2000).

5. Jones, D. L. Encyclopaedia of Ferns (Lothian, Melbourne, 1987). 